Patricia dos Santos Pessoa

Centro Universitário Unifieo, Osasco/SP

E-mail: pessoapaty@gmail.com

(9) https://orcid.org/0000-0003-0718-8897

Márcia Siqueira de Andrade

Fundação Instituto de Ensino Para Osasco - FIEO, Brasil

E-mail: marciandrade.ilapp@gmail.com

https://orcid.org/0000-0001-6278-7302
Recebido em: 23/04/2019

Aprovado em: 11/09/2019

\section{Práticas de leitura e desempenho na escrita de alunos do ensino médio}

\author{
Patricia dos Santos Pessoa \\ Márcia Siqueira de Andrade
}

\section{Resumo}

O objetivo desta pesquisa é verificar a relação entre desempenho na disciplina de língua portuguesa, variáveis sociodemográficas e práticas de leitura de aluno de ambos os sexos, regularmente matriculados no Ensino Médio no período noturno de escola da rede pública do Estado de São Paulo. Foi aplicado questionário semiestruturado organizado em dois campos: caracterização sociodemográfica e práticas de leitura. Também foram realizadas duas sessões de grupo focal e coletadas as notas atribuídas a cada participante na disciplina de língua portuguesa nos anos de 2014 e 2015. Os dados quantitativos foram analisados pela estatística descritiva (média e desvio - padrão). A análise dos dados textuais foi feita pela Classificação Hierárquica Descendente. Os resultados indicaram baixo desempenho na disciplina de língua portuguesa (média de 5,83) e baixa frequência de leitura $(69 \%)$. Foi observado também que o melhor desempenho foi de alunos do sexo feminino que estavam concluindo o Ensino Médio. Os depoentes declararam aumento na frequência diária de leitura e maior dificuldade na compreensão nesta mesma etapa do Ensino Médio. Em relação ao gênero literário, declararam preferir aventura e ficção. De acordo com os depoentes, os professores são os que mais incentivam a leitura, seguidos da família e apontam como motivo principal do desinteresse pela leitura escolar a pouca autonomia dos alunos na escolha dos textos e a metodologia empregada pelos professores nas aulas. Conclui-se pela necessidade de estudos em diferentes contextos como forma de aprofundar a compreensão da relação entre leitura e desempenho na língua portuguesa.

Palavras-chave: Leitura, Ensino Médio, Língua Portuguesa 
Abstract

Keywords:

Reading,

Secondary

Education,

Portuguese

Language.

\section{Reading practices and performance in the writing of middle school students}

The objective of this research is to verify the relationship between the performance, sociodemographic variables and reading practices of the Portuguese language of both gendersregularly enrolled in the evening shift of the Sao Paulo State public schools. A semistructured questionnaire was organized in two fields: sociodemographic characterization and reading practices. Two focus group sessions were also held and the scores awarded to each participant in the Portuguese language course in 2014 and 2015 were collected. The quantitative data was analyzed by descriptive statistics (mean and standard deviation). The analysis of the textual data was made by the Descending Hierarchical Classification. The results indicated low performance (mean of 5.83) and low reading frequency (69\%) in the Portuguese language subject. In addition, there was a better performance of female students, and of high school senior students. The interviewees declared an increase in the daily frequency of reading and greater difficulty in understanding this same stage of high school. In relation to the literary genre, they declared to prefer adventure and fiction. According to the interviewees, the motivation for reading comes first from the teachers, followed by the family, and they point out that the main reason for the lack of interest in reading in school is the low autonomythey have in choosing the texts and the methodology used by teachers in classes. We conclude by the need for studies in different contexts as a way to deepen the understanding of the relationship between reading and performance in the Portuguese language.

\section{Resumen}

Palabras clave: Lectura. Escuela. Portugués.

\section{Prácticas de lectura y rendimiento en la escrita de alumnos de la enseñanza medio}

El objetivo de esta investigación es estudiar la relación entre el rendimiento en la disciplina del portugués, variables sociodemográficas y las prácticas de lectura del estudiante de ambos sexos matriculados en la escuela secundaria en la escuela nocturna del estado de la red pública de São Paulo. Se aplicó cuestionario semiestructurado organizado en dos campos: caracterización sociodemográfica y de prácticas de lectura. También hubo dos sesiones de grupos focales y se recogen las puntuaciones otorgadas a cada participante en la disciplina portugués en los años 2014 y 2015. Los datos cuantitativos se analizaron utilizando estadística descriptiva (media y estándar - desviación). El análisis de los datos textuales fue realizado por la clasificación jerárquica descendente. Los resultados indicaron un rendimiento deficiente en el curso de portugués (media de 5,83) y baja frecuencia de lectura (69\%). Además, hubo mejor desempeño de las alumnas del sexo femenino y mejor desempeño de los alumnos concluyentes de la Enseñanza Media. Los participantes declararon aumento en la frecuencia diaria de lectura y mayor dificultad en la comprensión en esta misma etapa de la Enseñanza Media. En cuanto al género literario, declararon preferir aventura y ficción. De acuerdo con los responsables, los profesores son los que más incentivan la lectura, seguidos de la familia y apuntan como motivo principal del desinterés por la lectura escolar la poca autonomía de los alumnos en la elección de los textos y la metodología empleada por los profesores en las clases. Los resultados confirmaron la necesidad de estudios en diferentes contextos como una manera de profundizar en la comprensión de la relación entre la lectura y el rendimiento en portugués. 


\section{Introdução}

Este artigo tem como foco a leitura no Ensino Médio. Entende-se leitura como meio de conhecimento e compreensão de uma realidade social que ultrapassa a ideia de simplesmente codificar símbolos gráficos (Bezerra, Loureiro \& Maldonado, 2001). É pela leitura que o indivíduo constrói uma visão reflexiva e crítica da realidade na qual está inserido. A leitura é entendida, ainda, como um processo cultural em que "o significado dos textos depende das capacidades, das convenções e das práticas de leitura próprias das comunidades que constituem, na sincronia ou na diacronia, seus diferentes públicos" (Chartier, 2009, p. 37).

Essa concepção de leitura é descrita pelos Parâmetros Curriculares Nacionais (MEC, 1999) e as diretrizes curriculares para o Ensino Médio, que propõem uma articulação entre as práticas de leitura escolar e as práticas sociais para que o aluno aprenda de forma contextualizada e desenvolva a crítica ao ler o mundo e ao escrever sobre ele. Esse é o desafio da escola, que vai além da alfabetização do aluno, ou seja, ensinar o domínio do código escrito. Cabe à escola tornar o aluno um indivíduo letrado, habilitando-o a usar a escrita em atividades comunicativas e culturais e a compreender o mundo de forma crítica e contextualizada.

O desempenho de estudantes no ensino médio em português no ano de 2015 foi pior que há 20 anos. A etapa é tida como um dos principais gargalos do ensino básico, concentrando os piores indicadores. Os números são do Sistema de Avaliação da Educação Básica (SAEB), calculados a cada dois anos. A proficiência considerada adequada para o ensino médio é 300 em português segundo critério consolidado pelo Programa "Todos pela Educação", que leva em conta o desempenho dos países da Organização para a Cooperação e Desenvolvimento Econômico (OCDE) na avaliação internacional do Programa Internacional de Avaliação de Estudantes (Pisa).

Em 2015, a proficiência média em Língua Portuguesa na etapa de ensino foi 267,06 abaixo dos 268,57 obtidos em 2011 e dos 290, registrados pelos estudantes de 1995. As médias de 2015 colocam os estudantes do Ensino Médio no nível 2 de 8, de acordo com escala do MEC, em português. Isso significa que os alunos têm dificuldades em interpretações de texto (AGÊNCIA BRASIL, 2016). Diante desta realidade, é comum ouvir comentários como “os jovens não sabem ler” ou “os jovens não gostam de ler". Esses comentários nortearam o caminho que levou à busca pela compreensão das práticas de leitura dos adolescentes.

\section{Pensamento e linguagem}

A fundamentação desta pesquisa baseia-se em Vygotsky (1991 \& 2008), pois sua teoria norteia-se na concepção sócio- histórica e destaca que a construção do sujeito é mediada através das relações. Neste contexto, serão abordadas também as relações entre pensamento, linguagem, leitura e escrita. O 
desenvolvimento cognitivo se dá por meio da interação social, ou seja, da interação com outros indivíduos e com o meio (Vygotsky, 1991).

Neste sentido, Azevedo (2007, p. 19) afirma que “[...] a construção deste mundo se faz por meio da interação com o outro pela linguagem, a qual é considerada como característica fundamental do homem, visto como ser social". Para a autora, o conhecimento nasce a partir da construção que há entre as pessoas através da interação social. O sujeito está inserido na sociedade, estabelece relações com o outro, e sua história e desenvolvimento estão interligados à dimensão social, além dos fatores biológicos (Mello \& Teixeira, 2012; Azevedo, 2007).

Nessa perspectiva, Azevedo (2007, p.16) complementa que "Os homens em conjunto produzem um ambiente humano, com a totalidade de suas formações socioculturais e psicológicas". Para a efetivação da interação social, a linguagem surge como processo fundamental e como principal instrumento de comunicação. Para Vygotsky (2008), a função primordial da linguagem é a comunicação, o contato social. A comunicação cria vínculos e é fundamental para que os indivíduos se efetivem como seres sociais (Azevedo, 2007; Mello \& Teixeira, 2012).

A linguagem é constituinte do pensamento, da consciência, da vontade, das funções mentais superiores e do comportamento consciente: atenção voluntária, percepção, memória, pensamento (Azevedo, 2012; Molon, 2000). Nesse contexto, Azevedo (2007) diz: “A linguagem é para nós o que a água é para o peixe; nossa vida social existe por causa da linguagem que desenvolvemos" (Azevedo, 2007, p.19).

Pensamento e linguagem têm suas raízes genéticas diferentes e se desenvolvem de formas distintas e independentes. No primeiro momento, pensamento e linguagem são linhas independentes; ou seja, não há pensamento: “a própria consciência é uma construção da linguagem, não há consciência fora delas" (Azevedo, 2007, p.22).

No início, a fala segue a ação, concomitante a provocação e sendo dominada pela atividade. Mas, posteriormente surge uma nova relação entre palavra e ação, na qual a fala começa a dirigir, determinar e dominar o curso da ação, surgindo o que Vygotsky entende como função planejadora da fala para além da existência da linguagem, possibilitando a reflexão do mundo exterior (Vygotsky, 1991). Para Vygotsky (2008), "De início, a palavra é um substituto convencional do gesto; aparece muito antes da crucial descoberta da linguagem por parte da criança, e antes que ela seja capaz de operações lógicas” (Vygotsky, 2008, p.37).

Nessa mesma perspectiva, Vygotsky (1991) assinala que existe uma mudança significativa na habilidade da criança quanto ao uso da linguagem quando ela percebe que pode construir a solução de sua fala sem precisar dirigir-se a um adulto, constituindo, então, a fala socializada. Diante desses pressupostos, o autor também diz que, a partir do momento em que as crianças passam a ter autonomia de 
comportamento, elas se organizam em suas atividades, conseguindo com eficácia colocar-se numa atitude social.

A fala socializada é internalizada e elas passam a compreender que, em vez de se direcionar a um adulto, ela consegue se desenvolver dando fundamento à linguagem que passa a ser uma função de seu uso interpessoal, constituindo o que o autor denominou pensamento verbal. O pensamento verbal não se torna uma forma de comportamento natural, mas é um processo histórico-cultural que engloba pensamento e linguagem.

O pensamento e a linguagem, que até este momento desenvolviam-se separadamente, encontramse para iniciar um novo momento do desenvolvimento (Vygotsky, 2008 \& Azevedo, 2012). Neste contexto, Vygotsky (2008) ainda ressalta que:

Nessa idade, a criança conhece apenas as palavras que aprende com outras pessoas. Agora a situação muda: a criança sente a necessidade de palavras, e ao fazer perguntas, tenta afetivamente aprender os signos vinculados aos objetos. Ela parece ter descoberto a função simbólica da palavra. A fala, que na primeira fase era afetivoconativa, agora passa para a fase intelectual. As linhas do desenvolvimento da fala e do pensamento se encontram (Vygotsky, 2008, p.53,54).

Quando as linhas do desenvolvimento ora divergentes se encontram, o pensamento torna-se verbal e a fala racional. Neste sentido, de acordo com Vygotsky (2008), o percurso do desenvolvimento da fala segue o mesmo curso e as mesmas leis que todos os outros desenvolvimentos naturais da criança, como o ato de contar ou a memorização. Desse modo, segundo o autor, "O pensamento verbal, entretanto, não abrange de modo algum todas as formas de pensamento ou de fala. Há uma vasta área do pensamento que não mantém relação direta com a fala" (Vygotsky, 2008, p.59).

O desenvolvimento das estruturas gramaticais da criança se manifesta antes que ela tenha essa compreensão internalizada, pois ela pode agir com operadores, tais como "porque", "se", "quando" e "mas", antes de aprender (essas) relações causais, condicionais, temporais e de oposição. Então, há o domínio da sintaxe da fala antes da sintaxe do pensamento (Vygotsky, 2008).

Vygotsky (1991) faz também uma crítica ao ensino da escrita: "Ensinam-se as crianças a desenhar letras e construir palavras com elas, mas não se ensina a linguagem escrita. Enfatiza-se de tal forma a mecânica de ler o que está escrito que se acaba obscurecendo a linguagem escrita como tal” (Vygotsky, 1991, p.70). O autor enfatiza que, para ensinar a ler e a escrever, se faz necessário que, além da prática, o professor possa desenvolver um procedimento científico efetivo para o ensino de linguagem escrita às crianças.

Nessa perspectiva, o autor menciona que a linguagem escrita é diferente da língua falada, pois esta a criança desenvolve por si mesma, entretanto o ensino da língua escrita depende de um treinamento que requer atenção e esforços tanto do professor quanto do aluno. Ele traz consigo a percepção de que há preocupação excessiva com o desenvolvimento natural das crianças, mas não com as habilidades que lhe precisam ser ensinadas. 
Mediante a esse pressuposto, ele ainda enfatiza que a linguagem escrita é constituída por um sistema de signos que podem designar os sons e as palavras da linguagem falada, por intermédio das relações. Vygotsky (1991) ainda afirma que há descontinuidades no desenvolvimento da linguagem escrita nas crianças e que em dados momentos essa linha parece desaparecer completamente, quando que aparentemente de uma súbita, surge uma nova linha, que compreende a continuidade entre a velha e a nova. Ele ressalta que:

A primeira tarefa de uma investigação científica é revelar essa pré-história da linguagem escrita; mostrar o que leva as crianças a escrever; mostrar os pontos importantes pelos quais passa esse desenvolvimento pré-histórico e qual a sua relação com o aprendizado escolar. Atualmente, apesar dos vários estudos existentes, ainda não estamos em condições de escrever uma história coerente ou completa da linguagem escrita nas crianças (Vygotsky, 1991, p.71).

Diante da afirmação citada, podemos inferir que o autor preocupa-se com os aspectos relacionados aos processos de escrita da criança, levando em consideração o seu aspecto genético. Ele diz ainda que "o gesto é o signo visual que contém a futura escrita da criança, assim como uma semente contém um futuro orvalho" (Vygotsky, 1991, p.71). O autor compara os gestos com a escrita no ar, como reprodução de um signo gráfico e destaca dois domínios em que os gestos se ligam à origem dos signos escritos: o primeiro é o rabisco das crianças, traços que refletem o complemento da representação gestual. E o segundo, que consiste na união dos gestos com a linguagem escrita, são os jogos infantis. Nesse sentido, enfatiza a importância do brincar para a aprendizagem da escrita, uma vez que com ela a criança faz associações entre objeto e signo.

Vygotsky (1991) ainda destaca que os educadores precisam organizar ações para o complexo processo referente à transição de um tipo de linguagem escrita para o outro e que cabe a eles também o acompanhamento neste processo.

A leitura perpassa por um trabalho ativo de compreensão e interpretação do texto, que abrange objetos específicos. Então, para os PCN (2001), a leitura é:

[...] o processo no qual o leitor realiza um trabalho ativo de compreensão e interpretação do texto, a partir de seus objetivos, de seu conhecimento sobre o assunto, sobre o autor, de tudo que se sabe sobre a linguagem, etc. Não se trata de extrair informações, decodificando letra por letra, palavra por palavra. Trata-se de uma atividade que implica estratégias de seleção, antecipação, inferências e verificação, sem os quais não é possível proficiência. (PCN, 2001, p.69).

Há na literatura muitas definições de leitura. Para Campos (2006), a leitura é uma atividade que envolve a recriação e a reconstrução de ideias, enquanto um processo dinâmico, construído na interação da informação situada no texto e o conhecimento prévio do leitor, tornando possível a construção de sentido e a compreensão textual (Campos, 2006). Para Azevedo (2012):

A leitura é a realização do objetivo da escrita; quem escreve o faz para ser lido. O mundo da escrita é complicado e caótico no aspecto gráfico, mas se ainda a isso não for juntado o 
mundo dos significados carregados pela escrita. A leitura vai operar justamente nesse universo. Às vezes, ler é um processo de descoberta, como a busca do saber científico; portanto, deve ser construído individualmente (Azevedo, 2012. p.28).

Rauen (2008) destaca que a leitura é a base fundamental para a formação da cidadania. É necessário que o professor se estabeleça como aquele que educa para as potencialidades do ser, tanto individual como socialmente. Ele precisa ter uma postura leitora e reflexiva sobre o significado do ato de ler (Rauen, 2008).

Silva (2015) destaca que pela leitura é possível aperfeiçoar as habilidades de antecipação e levantamento de hipóteses a respeito do conteúdo a ser lido. E é dessa forma que o sujeito consegue construir sua própria autonomia leitora (Silva, 2015). Soares (2000) aponta que a leitura não é um ato solitário; é interação verbal entre os indivíduos socialmente determinados envolvendo a estrutura social, as relações com o mundo e com os outros.

Retornando a Rauen (2008), o ato de ler não representa apenas fatores intelectuais, mas uma condição de liberação, pois fornece ao leitor autonomia para as mais variadas linguagens que o rodeiam, independente das perspectivas de mundos diferentes do seu. Neste sentido, Rocha, Melo \& Lopes (2012) compreendem que aprender a ler não é apenas um processo cognitivo, mas é também uma atividade social e cultural que corroboram para a criação de vínculos culturais e de conhecimento.

Chartier (1991) afirma que se faz necessário reconstruir as maneiras próprias de ler para cada comunidade de leitores, pois cada leitor a partir de suas próprias referências: individuais, sociais, históricas e existenciais faz uma apropriação ao texto, daquilo que fornece a ele mais sentido. Então, é fundamental compreender como se dá a apropriação dos textos diante das variadas formas de entendimento. Desse modo, a leitura torna-se uma arte com instrumento de valor cultural. Ler é infligir sentido ao texto, contudo relacionando-o com as experiências prévias do leitor (Rosa, 2005).

Toda leitura tem um aspecto de decifração e de decodificação; essas atividades devem possuir um equilíbrio entre dois aspectos (significado / significante), caso contrário, haverá o risco de destruir a linguagem humana naquilo que possui como princípio fundamental (Azevedo, 2007). Entretanto, compreende-se leitura no seu entendimento como um todo, utilizando-se dela para fazer suas reflexões e críticas de acordo com o que se lê. A leitura deve ser uma prática prazerosa, um caminho para a descoberta de si e do outro como ser pensante. (Brandão \& Micheletti, 2002).

Leitura e escrita estão interligadas com a forma de se compreender o mundo, são fundamentais no processo de alfabetização construídas paralelamente (Azevedo, 2007; 2012). Silva (2015) destaca que os processos relacionados à leitura perpassam por caminhos que vão para além da alfabetização, afirma que o leitor tem a necessidade de ser letrado, ou seja, ele precisa compreender os mecanismos da leitura e da escrita. 
Dessa forma, Quiosa (2004) aborda que o domínio da língua escrita está para além da compreensão do texto, visto que abrange também a capacidade de compreender os diversos gêneros textuais e suportes que estão dentro dos contextos sociais: charge, piada.

Uma pessoa alfabetizada já consegue ter noções sobre as formas de leitura, embora o processo de tornar-se um leitor autônomo possa levar mais tempo. Tornar-se alfabetizado é adquirir habilidades para ler e escrever, construindo práticas sociais de leitura e escrita, gerando competências que alteram os aspectos sociais, culturais, cognitivos (Silva, 2015).

A escrita é um modo de representação da memória coletiva, religiosa, científica, artística e cultural dentro de uma sociedade e promove a comunicação eficaz (Silva, 2015). Aprender a escrever é ir além do processo de reconhecimento das palavras e das frases, é levar em conta os significados estabelecidos social e culturalmente (Azevedo, 2007).

Azevedo (2012) afirma ainda que há na escola várias formas para a transmissão do conhecimento, mas enfatiza que o instrumento mais significativo é a leitura e a escrita. A autora aponta leitura e escrita como aspecto fundamental para que o cidadão possa tornar-se atuante, crítico e participativo considerando as decisões que emergem no contexto social.

A escola é o ambiente apropriado para o incentivo de ambas, proporcionando ao aluno a oportunidade de conhecimentos mútuos para a organização da estrutura de seus pensamentos, visto que dessa maneira, poderá levá-lo a autonomia leitora; e este é um desafio da escola. Neste sentido, há necessidade de fazer da escola um ambiente em que a leitura e a escrita possam ser práticas coerentes, um local em que se permita ler e escrever para repensar o mundo (Lerner, 2005).

Amaral \& Souza (2010) ressaltam que o leitor nasce a partir de um interesse empírico, do incentivo que lhe é passado no meio em que vive e sua continuação posterior na escola, que é transmitida por professores ao longo de sua trajetória escolar. O professor exerce papel importante para a formação de leitores, pois pode organizar situações para que o aprendizado o conduza a esse objetivo.

Para Rauen (2008), ensinar a ler é a função primordial da escola, sobretudo também é fundamental ampliar o domínio dos níveis de leitura e escrita, e orientar os alunos quanto aos materiais a serem utilizados neste processo. Lerner (2005) afirma que a função da escola é levar os alunos à compreensão do que se lê de forma autônoma e colocar as suas inferências pessoais. E cabe à escola proporcionar o estímulo à leitura, melhorando suas estratégias no que diz respeito à sua compreensão, que é um dos problemas relacionados à aprendizagem.

Cabe ao professor desenvolver estratégias para que o aluno tenha gosto por leitura, fazendo com que essa aproximação possa ser significativa, de acordo com sua história e suas necessidades. Ela precisa ser estimulante, reflexiva, diversificada, crítica, de modo que possa ensinar aos alunos que a prática da leitura favorece uma vivência melhor. Neste contexto, Rauen (2008) destaca que é importante que o 
professor se apresente aos alunos como leitor participante, envolvido com a prática de ler e que possa transmitir o seu valor para o desenvolvimento intelectual, crítico e criativo.

Os educadores podem fortalecer o educando rumo à autonomia como leitor partindo de uma mediação leitora que facilite a compreensão do texto. É pela mediação que se agregam conhecimentos tanto da leitura quanto da escrita, pois propicia uma nova significação para o diálogo entre o leitor e o texto. Desse modo, a escola faz o papel fundamental quanto à mobilização e sensibilização dos alunos para a leitura (Gouveia, 2009; Silva, 2015).

Dessa forma, o leitor deve se identificar com a sua leitura, que estará diretamente relacionada com sua vida, experiências, para que a sua prática não fique privada de sentido (Moro, Souto \& Estabel, 2013). Gonçalves (2013) diz que a prática da leitura enriquece o vocabulário, possibilita a inovação de conhecimentos, o raciocínio e a interpretação. Neste sentido, o leitor irá despertar para conhecimentos novos, para o mundo real e transcenderá para o entendimento do outro ser.

A prática da leitura torna-se indispensável para que o sujeito seja inserido na sociedade e eficiente a sua formação enquanto cidadão, possibilitando sua reflexão crítica, gerando mudanças sociais que possam causar impacto, pois, ao ler um texto, empiricamente o sujeito faz associações a seus próprios valores, crenças e atitudes, favorecendo uma análise crítica da sociedade já que, com a leitura, além de decodificar, pode compreender, investigar, analisar e ponderar sobre diversas questões de cunho pessoal e social (Silva, 2015; Rosa, 2005).

Dessa forma sentido, Blank (2009) afirma que a prática da leitura torna-se presente desde o momento em que se inicia a compreensão do mundo e da sociedade à sua volta, pois há no ser humano constante desejo para se perceber e proporcionar sentido e significado às suas percepções, articulando aspectos da ficção com a vida real. Concomitantemente Silva (1998), destaca que:

A leitura crítica encontra a sua principal razão de ser nas lutas em direção à transformação da realidade brasileira, levando o cidadão a compreender as raízes históricas das contradições e a buscar, pela ação concreta, uma sociedade onde os benefícios do trabalho produtivo e, portanto, da riqueza nacional não sejam privilégios de uma minoria. (Silva, 1998, pp. 22-23).

Moro, Souto \& Estabel (2013) destacam que o uso das tecnologias também proporciona a prática de leitura entre os adolescentes, embora este tema seja polêmico nos debates relacionados à educação. A internet foi um meio de comunicação que cresceu e se expandiu de forma abrangente no mundo. Ela disponibiliza acervo de bibliotecas digitais e virtuais, expandindo, dessa forma, os limites do ensino e da pesquisa.

Para o incentivo da leitura foi criado no Brasil o Programa Nacional Biblioteca da Escola (PNBE - Portaria Ministerial $n^{0}$ 584, abr./1997), que tem como objetivo prover as escolas de ensino público das redes Federal, Estadual, Municipal e do Distrito Federal, no âmbito da educação infantil (creches e pré- 
escolas), do Ensino Fundamental, do Ensino Médio e Educação de Jovens e Adultos (EJA), com o fornecimento de obras e demais materiais de apoio à prática da educação básica.

Nesse programa, são distribuídos às escolas diversos acervos compostos por obras tais como: literatura, referência, pesquisa e de materiais sobre as mais diversas áreas do conhecimento, para que alunos e professores possam formar-se leitores (FNDE, 2015). Há uma estreita relação entre a prática de leitura e o leitor proficiente, sendo o último aquele que se apresenta engajado, que consegue antecipar o material e formular imagens em sua mente, pois seu conhecimento prévio também define o que está no papel e não apenas a leitura propriamente dita, pois ele conhece e reconhece os padrões ortográficos.

Também é aquele que tem a capacidade de acessar textos diversos em contextos diferenciados, interagir com eles, conseguindo absorver conhecimentos para as situações de sua vida social e cultural (Silva, 2015). A leitura possibilita não apenas informações para crescimento pessoal, mas compreende também o entretenimento, o imaginário, a criação e a liberdade do indivíduo (Thomazi, 2005). Nesse contexto, os PCN (2001, p.54) afirmam que "formar um leitor competente supõe formar alguém que compreende o que lê; que possa aprender a ler também o que não está escrito”.

Além disso, ler é básico para o avanço do desenvolvimento na aprendizagem de qualquer assunto. Então, para que se estabeleça um leitor proficiente, é necessário motivação também através dos profissionais da educação, pois são eles que, muitas vezes, adquirem os recursos e materiais que possam promover envolvimento com a leitura, seja através de livros, revistas, cartazes, panfletos, jornais, internet ou outros meios que possam facilitar e cooperar com o procedimento para que haja o seu desenvolvimento. Vale destacar que o ato de ler é a efetivação da prática da escrita, sendo que aquele que escreve, o faz para ser lido (Silva, 2011; Azevedo, 2007).

\section{Metodologia}

Os dados foram coletados em Escola da Rede Estadual da Diretoria de Ensino do Estado de São Paulo, situada na Zona Oeste da cidade de Osasco, existente há quarenta anos.

Participaram da pesquisa cinquenta e dois alunos de ambos os sexos, regularmente matriculados no Ensino Médio, período noturno. Para a coleta de dados, foi utilizado um questionário organizado em dois campos: caracterização do aluno e práticas de leitura e notas dos dois últimos anos da disciplina de língua portuguesa, e audiogravação das sessões do grupo focal.

Foram 52 participantes sendo $77 \%$ nos $1^{\circ}$ e $2^{\circ}$ anos igualmente divididos e $23,1 \%$ no $3^{\circ}$ ano. A idade média dos participantes está em 16,23 anos $(\mathrm{DP}=1,04)$ variando entre 15 e 19 anos. Sendo que 9,6\% dos participantes superaram a idade regular de 17 anos para a conclusão do Ensino Médio. Em relação ao sexo, $65 \%$ são do sexo feminino e $35 \%$ do sexo masculino. 


\section{Análise dos dados}

Verificou-se que, no período analisado, as meninas tiveram melhor desempenho em 2014: $\mathrm{M}=5,88 ; \mathrm{DP}=1,12$ e 2015, $\mathrm{M}=5,32 ; \mathrm{DP}=1,24(\mathrm{M}:$ Meninas e DP: Desvio Padrão é a média do desempenho das meninas em relação aos meninos). Em relação à escolaridade, identifica-se aumento da média em língua portuguesa nos dois anos considerados, 2014 e 2015, o que sugere um melhor desempenho dos alunos no final do Ensino Médio nessa disciplina, no período considerado.

Sobre o aspecto da frequência de leitura, $50 \%$ dos participantes responderam que leem com frequência. Mas, o aumento acontece para os alunos do terceiro ano do Ensino Médio, que tem o avança de $45 \%$ para $67 \%$.

A análise dos dados apresentados parece confirmar o aumento da leitura diária declarada por alunos do terceiro ano do Ensino Médio: 41,67\%. Já entre alunos do primeiro ano, a leitura diária foi declarada por $20 \%$ e $15 \%$ por alunos do segundo ano. De qualquer forma, os resultados indicam que a maioria dos participantes $(51,93 \%)$ declarou ler esporadicamente, menos de duas vezes por semana. De acordo com as respostas, os professores são os que mais incentivam a leitura, com $37,10 \%$, seguidos da família, com 33,87\%. Em relação ao gênero literário, os preferidos foram aventura, seguidos por ficção.

No total geral, $76,92 \%$ dos participantes afirmam que compreendem o que leem; $23,08 \%$ não compreendem. Entretanto, separadamente, $70 \%$ dos participantes matriculados no segundo ano, afirmam compreender a leitura que realizam. Já no terceiro ano, 16,67\% apontam dificuldades na compreensão de textos. É possível inferir que, embora os alunos nos anos finais do Ensino Médio leiam mais, a compreensão diminui.

Referente ao resultado do grupo focal, destaca-se que a leitura escolar, a tecnologia e os gêneros literários são importantes para os participantes respondentes. Os participantes compreendem que a leitura abrange o aprendizado e as descobertas de novos ambientes mesmo sem ter ido de fato ao local, o que contribui para a afirmação de Rosa (2005), pois atribuem à leitura a identidade de instrumento cultural para favorecer experiência, conhecimento e concepções de mundo.

Há uma compreensão por parte dos participantes de que a leitura e a escrita são importantes para a sua formação tanto escolar quanto social. Para os participantes, a leitura é importante em todas as disciplinas escolares, pois trará conhecimentos prévios que contribuem para além do contexto escolar, enriquece o vocabulário e melhora a escrita. Eles explicam que as leituras solicitadas pelos professores são difíceis, não são temas significativos para eles, por isso as aulas tornam-se cansativas e desinteressantes. Há consciência da importância da escola para o incentivo da leitura, mas reconhecem que a falta de interesse de alguns alunos torna difícil a contribuição do professor. 
Para os participantes, a escola deveria conhecer o que eles realmente gostam de ler, deixando-os mais livres em suas escolhas, trabalhando de acordo com essas temáticas. Sugerem que os professores poderiam associar as leituras a outras fontes de informação, como vídeos, filmes, revistas, favorecendo o conhecimento prévio significativo. As palavras dos participantes contribuem com o que afirmam Moro, Souto e Estabel (2013): que as tecnologias promovem a prática de leitura entre os adolescentes. Afirmam ainda que o uso da internet cresceu e se expandiu, disponibilizando diversos arquivos digitais e virtuais que podem estar ao alcance de todos e facilitar o dia a dia dos estudantes.

Os participantes afirmam que a leitura escolar é muito formal, tornando a aprendizagem mais difícil. Fazem críticas quanto à forma como os professores solicitam as leituras no contexto escolar. Para eles, a preocupação maior não deveria ser apenas a resolução de situações escolares, mas o envolvimento com o contexto em que eles estão inseridos e levá-los a uma reflexão mais intensa, proporcionando-lhes conhecimentos para além das disciplinas escolares. Para eles, a leitura escolar serve somente para fazer interpretações de texto e estas não possuem significados para os alunos. Os estudantes afirmam que ler algo de seu interesse pessoal os torna leitores autônomos e a leitura passa a ser mais interessante.

\section{Discussão}

Os resultados apresentados indicam baixo desempenho dos participantes na disciplina de língua portuguesa, média de 5,8 pontos de um máximo de dez, que acontece também nas avaliações brasileiras em larga escala. O Sistema de Avaliação da Educação Básica (SAEB) indica que o desempenho em língua portuguesa dos alunos da $3^{a}$ série do Ensino Médio piorou entre os anos de 1995 e 2005. O desempenho médio dos alunos da $3^{\mathrm{a}}$ série do ensino médio em língua portuguesa decaiu aproximadamente $11,1 \%$, passando de uma média nacional de 290,0 pontos para 257,6 pontos.

Verificou-se, porém, um melhor desempenho na língua portuguesa de alunas do sexo feminino, tanto no ano de 2014 (5,88 das meninas contra 5,72 dos meninos) quanto em 2015 (5,32 das meninas contra 5,27 dos meninos). E isso tem sido apontado na literatura científica. Destacam-se os desenvolvidos por Oliveira \& Santos, (2006), Chapman (1995), Hoskins, Newsted e Dennis (1997) e Nowell e Hedges (1998), dentre outros, que apontam para um melhor rendimento das mulheres em relação aos homens. Sila \& Santos (2004) também constataram que as mulheres apresentaram melhor desempenho do que os homens quando comparados em função das variáveis: compreensão em leitura e desempenho acadêmico.

A formação de um leitor, na concepção dos PCN (2001), pressupõe que ele compreenda o texto e que aprenda a entender até mesmo o que não está escrito, pois ler é uma atividade que abrange aspectos de seleção, antecipação, inferência e verificação. Considerando o grau de proficiência leitora, os resultados mostram relação inversa entre compreensão da leitura e anos de escolaridade, ou seja, os 
alunos declaram maior dificuldade de compreensão ao final do Ensino Médio. Essa situação reflete o resultado de outras pesquisas sobre o tema: Oliveira \& Santos (2006) relatam melhor desempenho na compreensão de textos por alunos mais jovens.

Silva (1998), afirmando que a leitura crítica, contribui para a transformação da realidade brasileira, pois leva o leitor a uma busca contínua por uma ação concreta para encontrar benefícios em seu trabalho produtivo e para que isso não seja apenas um privilégio de poucas pessoas. Embora os participantes indiquem os professores como os principais incentivadores de práticas de leitura, destacando seu papel fundamental para a motivação e o interesse, também apontam a necessidade de esse profissional compreender o que os alunos gostam de ler, deixando-os mais livres em suas escolhas, trabalhando a partir dos textos escolhidos.

Nesse sentido, Moro, Souto \& Estabel (2013) confirmam que o leitor tem a necessidade de se identificar com a leitura, destacando que esta precisa estar relacionada de forma direta com a vida e as experiências do sujeito leitor para que possa contribuir de forma significativa. Para Lerner (2005), o principal incentivo da leitura acontece no ambiente escolar, favorecendo a estruturação e organização do pensamento. Silva (2011) reafirma a importância dos profissionais da educação como motivadores da leitura. Rauen (2008) contribui afirmando que, no processo de leitura, o professor tende a ser o mediador.

Rauen (2008) ainda coloca que a capacitação leitora dos alunos não pode ser feita sem a mediação do educador e que é necessário que a leitura possa fazer parte da prática pessoal deste profissional. Santana (2008) contribui afirmando que o professor é o profissional que tem a capacidade de proporcionar mecanismos para que o gosto pela leitura seja eficiente e possa aproximar seus alunos da leitura. Neste contexto, Rosa (2005) afirma que a leitura contribui de forma social, que é uma prática iniciada na escola e tem sua continuação durante a vivência do aluno em suas relações que abarcam todo o seu contexto. Ressalta, ainda, que a leitura contribui para que se possa estabelecer a construção de cidadania do sujeito.

Apesar da afirmação dos participantes, referenciada pelos autores aqui indicados, apontando a escola e o professor como elementos principais para a prática de leitura, parece existir uma dicotomia entre leitura crítica, autônoma e leitura de sala de aula na percepção dos alunos. As estratégias utilizadas pelos professores, na visão dos alunos, denotam uma concepção de leitura mecanicista, destituída de sentido e significado.

Considera-se que os alunos deveriam ser capazes de "experienciar" o ato de ler como uma ação cultural, em que o leitor tem papel dinâmico nas redes de significação do texto. Vários autores analisam o processo de escolarização do ato de ler, tendo em vista as concepções de leitura que norteiam o trabalho 
dos professores em sala de aula. Para Kleiman (1996), a escola ainda prioriza a leitura como mera decodificação, pressupondo um leitor passivo, cuja participação volta-se primordialmente para a superfície do texto.

É justamente na troca de experiências e histórias de leitura que, de fato, ocorre a interação entre textos e leitores. Contudo, a escola parece não estimular a função interativa dessa prática ao privilegiar atividades que desmotivam o aluno e provocam a aversão dos educandos ao mundo dos livros. De acordo com Silva (1998, p.56), "em certo sentido, a leitura de textos se coloca como uma "janela para o mundo"”. Por isso mesmo, é importante que essa janela fique sempre aberta, possibilitando desafios cada vez maiores para a compreensão e decisão do leitor.

\section{Considerações Finais}

Este artigo buscou verificar a relação ente notas na disciplina de língua portuguesa, variáveis sociodemográficas e práticas de leitura de alunos regularmente matriculados no Ensino Médio de escola localizada na região oeste da grande São Paulo.

Os resultados fornecidos podem ser considerados como um trabalho de melhoria da prática docente, pois coloca em destaque a importância de se discutir em profundidade as práticas de leitura que acontecem nas salas de aula, especialmente no Ensino Médio, cenário desta pesquisa. A leitura parece ser uma prática pouco prazerosa entre os jovens que frequentam o Ensino Médio.

A leitura, de modo geral, parece estar vinculada às necessidades emergentes para a inserção cultural, pois leem os textos na busca pelas informações que necessitam naquele momento. Silva (1998) afirma que a escola forma "ledores", mas não consegue promover o desenvolvimento de leitores críticos, uma vez que, no contexto de sala de aula, a leitura é trabalhada como uma prática rotineira e mecânica. Ao sair da escola, o indivíduo geralmente abandona essa prática, pois encara tal atividade como algo atrelado aos exercícios escolares. Em sala de aula, a leitura consolida-se cada vez mais como atividade atrelada à obrigação da rotina de trabalho, ao passo que o ato de ler como forma lúdica e prazerosa de reconstruir mundos possíveis revela-se uma prática pouco discutida e concretizada.

Considera-se que a pesquisa foi conduzida com um número reduzido de participantes e as avaliações foram estabelecidas somente de acordo com a percepção dos alunos; professores não foram incluídos. Não obstante as limitações, a investigação pode ser considerada de alta relevância científica e social, uma vez que é mínima a literatura brasileira sobre a relação de desempenho em língua portuguesa e práticas de leitura baseada em evidências empíricas, e os resultados obtidos têm relevância para a prática pedagógica. 
Em se tratando de sugestão para futuras pesquisas, considera-se relevante uma coleta e análise de dados numa abordagem que considere aspectos qualitativos e quantitativos com análises estatísticas. Nesse sentido, será possível ampliar o grau de generalização dos resultados quantitativos.

\section{Referências}

AGÊNCIA BRASIL. Recuperado em 02 de janeiro de 2019. http://agenciabrasil.ebc.com.br/educacao/noticia/2016-09/desempenho-de-estudantes-doensino-medio-e-menorque-o-de-20-anos-atras

AGÊNCIA BRASIL. Recuperado em 02 de janeiro de 2019. http://agenciabrasil.ebc.com.br/geral/noticia/201601/enem-registra-maior-nota-dematematica-da-historia-do-exame

AMARAL, E. T. (2010). O professor de ensino médio e o seu olhar sobre a leitura e a escrita em sua disciplina. Dissertação de mestrado, Universidade Metodista de Piracicaba, UNIMEP. SP, Brasil. Recuperado em 02 de fevereiro de 2019, https://www.unimep.br/phpg/bibdig/pdfs/docs/10032011_115919_dissertacao.pdf

ANDRADE, M. S. (2011). Psicopedagogia clínica. Manual para diagnóstico. Osasco, São Paulo: Unifieo.

ANDRADE, M. S. \& Franco, M. L. P. B. (Orgs.), (2012). Livro: aprendizagem humana. Artigos: Leitura e escrita um direito de todos (Azevedo, C.). Em defesa da leitura (Barone, L. M. C.). São Paulo: Casa do Psicólogo.

AZEVEDO, C. (2007). A mediação da linguagem na construção da subjetividade. In: Andrade, M. S. \& Souza Neto, J. C. de (Orgs.). Análise institucional. Diferentes perspectivas de aprendizagem, São Paulo: Expressão e Arte, p. 13-36.

AZEVEDO, C. (2012). A práxis do professor alfabetizador e a aprendizagem. São Paulo: Expressão e Arte, p. 13 36.

BARTHOLOMEU, D., MONTIEL, J. M. S. \& MARJORIE C. R. (2014). Psicopedagogia, desenvolvimento humano e cotidiano escolar. São Paulo: Vetor.

BLANK,C. K. (2009). Práticas de leitura dos adolescentes das escolas de Ensino Médio do Rio Grande. BIBLOS, Rio Grande, Vol. 23, n², p.43-54. Recuperado em 02 de junho de 2015, http://basessibi.c3sl.ufpr.br/brapci/index.php/article/view/0000008447/a578b933ef5de3c1de9 75a225f4a9ccc

BRANDÃO, H. H. N. \& MICHELETTI, G. (2002), Teoria e prática da leitura. In: Coletânea de textos didáticos. Componente curricular leitura e elaboração de textos. Curso de Pedagogia em Serviço. Campina Grande: UEPB.

BRASIL. Ministério de Educação e Cultura. LDB- Lei n 9 9394/96, de 20 de dezembro de 1996. Estabelece as Diretrizes e Bases da Educação Nacional. Brasília: MEC, 1996. Recuperado em 04 de fevereiro de 2019, http://portal.mec.gov.br/seesp/arquivos/pdf/lei9394_ldbn1.pdf.

BRASIL. (1999). Ministério da Educação. Relatório Educação para todos. Versão preliminar. Recuperado em 05 de fevereiro de 2019, http://portal.mec.gov.br/index.php?option=com_docman\&view=download\&alias=15774eptrelatorio-06062014\&Itemid $=30192$

BRASIL. 2000). Ministério da Educação e do Desporto, Secretaria de Educação Fundamental. Parâmetros Nacionais Curriculares. Brasília: MEC/ SEF, 2000. Recuperado em 02 de fevereiro de 2019, http://portal.mec.gov.br/seb/arquivos/pdf/livro06.pdf

BRASIL. (2001). Ministério da Educação e do Desporto, Secretaria de Educação Fundamental. Parâmetros Nacionais Curriculares. Brasília: MEC/ SEF Recuperado em 10 de fevereiro de 2019, http://portal.mec.gov.br/seb/arquivos/pdf/14_24.pdf 
BRASIL. (2009). MEC - Ministério da Educação. Publicações. Recuperado em 02 de fevereiro de 2019, http://portal.mec.gov.br/programa-mais-educacao/publicacoes

BRASIL. (2014). Ministério da Educação. Relatório Educação para todos 2000-2015. Recuperado em 02 de fevereiro de 2019, http://portal.mec.gov.br/index.php?option=com_docman\&view=download\&alias=15774eptrelatorio-06062014\&Itemid=30192 Acesso em 18 de outubro de 2016. BRASIL. Plano Nacional de Educação PNE/ Ministério da Educação. Brasília, DF: INEP, 2016.

BRASIL. (2017). Ministério da Educação. Recuperado em 06 de fevereiro de 2019. http://portal.mec.gov.br/component/content/article?id=40361\#nem_01

BRASIL. MEC/INEP. Relatório do Sistema Nacional de Avaliação da Educação Básica (SAEB) - ciclo 1990. Brasília, Recuperado em 05 de fevereiro de http://www.abep.nepo.unicamp.br/docs/rev_inf/vol18_n1e2_2001/vol18_n1e2_2001_7artigo_111_130.pdf

CASTRO, C. A. \& Castellanos, S. L.V. (2009). Apropriações e representações sócio - históricas do trinômio leitura . Recuperado em 05 de fevereiro de 2019, https://periodicos.ufsc.br/index.php/eb/article/view/15182924.2009v14nesp1p42/19833

CHARTIER, R. (1991) Revista das Revistas - O mundo como representação. USP (SP)Vol. 05, n 11, p. 172-191 Recuperado em 07 de fevereiro de 2019, http://www.scielo.br/scielo.php?script=sci_arttext\&pid=S010340141991000100010

CHARTIER, R. (2007). Inscrever e apagar. Cultura escrita e literatura (séculos XI-XVIII). Tradução de Luzmara Curcino Ferreira, São Paulo: Editora da UNESP

CHARTIER, R. (2007). A história ou a leitura do tempo. Belo Horizonte: Autêntica Editora, 2009.

CHARTIER, R. (2007). (2009). (Org.). Práticas de leitura. Tradução de Cristiane Nascimento. Práticas de leitura. São Paulo: Estação Liberdade

CHARTIER, R. (2007). (2011). Práticas da leitura, 5a ed.. São Paulo: Liberdade.

DIAS, S.B; Matos, A. \& Silva, J.M. (2009). A evasão escolar no ensino médio: Um estudo de caso. V. 9 n ${ }^{\circ} 19$ $\begin{array}{llllll}\text { Recuperado } & \text { em } & 08 & \text { de } & \text { fevereiro } & \text { de }\end{array}$ http://www.seduc.go.gov.br/imprensa/documentos/Arquivos/15\%20\%20Manual\%20de\%20Gest\%C3\%A3o\%20Pe dag\%C3\%B3gico $\% 20 \mathrm{e} \% 20$ Administrativo/2.1

$0 \% 20$ Combate $\% 20 \% \mathrm{C} 3 \% \mathrm{~A} 0 \% 20$ evas $\% \mathrm{C} 3 \% \mathrm{~A} 3 \mathrm{o} / \mathrm{A} \% 20 \mathrm{EVAS} \% \mathrm{C} 3 \% 83 \mathrm{O} \% 20 \mathrm{ESCOLAR} \% 2$

0NO\%20ENSINO\%20M\%C3\%89DIO\%20-\%20UM\%20ESTUDO\%20DE\%20CASO.pdf

FNDE (2015) Fundo Nacional de Desenvolvimento da Educação, Ministério da Educação, Brasil. Recuperado em 14 de fevereiro de 2016, http://www.fnde.gov.br/fnde/acesso-a-informacao.

GLASSER, A. E. (2010). Campo da leitura: Disputas e significações na formação do leitor. LINGUASAGEM, São Carlos, Vol. 15, n 1, p. 01-14 - 2010 - ISSN - 1983-6988 41. Recuperado em 02 de setembro de 2015, http://www.letras.ufscar.br/linguasagem/edicao15/004.pdf

GOERGEN, P.(2005). Educação e valores no mundo contemporâneo. Revista Educação Social. V. 26 n $^{\circ} 92 \mathrm{pp}$. 983-1011. Recuperado em 10 de fevereiro de 2019, http://www.scielo.br/pdf/es/v26n92/v26n92a13.pdf

GONÇALVES, D.S.N. (2013). A importância da leitura nos anos iniciais. Monografia. Universidade do Estado do Rio de Janeiro. São Gonçalo - RJ. Recuperado em 09 de fevereiro de 2019,http://www.ffp.uerj.br/arquivos/dedu/monografias/dsng.pdf

GONDIM, S. M. G. (2002). Grupos focais como técnica de investigação qualitativa: desafios metodológicos. Paidéa ,12 (24), 149-161. 
GOUVEIA, J. M. (2009). Hábitos de leitura em crianças e adolescentes - um estudo de caso em alunos do terceiro ciclos do ensino básico. Dissertação de Mestrado,Universidade Portucalense, UPT, Porto, Portugal. Recuperado em 04 de abril de 2019, https://issuu.com/medull/docs/revista_psicologia_3

KLEIMAN, A (1996) Leitura e interdisciplinaridade: tecendo redes nos projetos da escola. 1996. Campinas: Mercado de Letras.

LERNER, D. (2005). Ler e escrever na escola: o real, o possível e o necessário, Porto Alegre: Artmed.

MELLO, E. de F. \& TEIXEIRA, A. C. (2012). A interação social descrita por Vygotsky e a sua possível ligação com a aprendizagem das tecnologias de rede. Recuperado em 09de fevereiro de 2019. http://www.portalanpedsul.com.br/admin/uploads/2012/Educacao_Comunicacao_e_Tecnolog ias/Trabalho/06_03_38_6-7515-1-PB.pdf

MOLON, S. I. (2000). III Conferência de Pesquisa Sócio- Cultural - Subjetividade do Sujeito em Vygotsky. Campinas - SP. Recuperado em 13 de fevereiro de 2019, http://www.scielo.br/scielo. php?script=sci_nlinks\&ref=000122\&pid=S01013289201200030000800007\&lng=pt

MORO, E. L. da S.; Souto, G. P. \& Estabel, L. B. (2013). A influência da internet nos hábitos de leitura do adolescente. Recuperado em 08 de fevereiro de 2019, http://gebe.eci.ufmg.br/downloads/313.pdf

OLIVEIRA, K. L. de, \& Santos, A. A. dos. (2006). Compreensão de textos e desempenho acadêmico. Psic: revista da Vetor Editora, 7(1), 19-27. Recuperado em 09 de fevereiro de 2019, http://pepsic.bvsalud.org/scielo. php?script=sci_arttext\&pid=S167673142006000100004\&lng=pt\&tlng=pt.

QUIOSA, A. S. (2004) Processos que permeiam a História ensinada. Recuperado em 24 de novembro de 2015, Disponível em: http://www.ufjf.br/virtu/files/2011/09/LEITURA-E-ESCRITA-PROCESSOSQUE-PERMEIAMA-HIST\%C3\%93RIA-ENSINADA.pdf

RAUEN, R.F. (2008). Práticas pedagógicas que estimulam a leitura. Recuperado em 12 de fevereiro de 2019,http://www.diaadiaeducacao.pr.gov.br/portals/pde/arquivos/390-4.pdf

ROCHA, E.C.F. ; Melo, M.B.O \& Lopes, D. (2012). A importância da leitura no processo de desenvolvimento da aprendizagem dacriança no Ensino Fundamental I. Revista Discentis - Revista Científica Eletrônica da Universidade do Estado da Bahia, Campus XVI - Irecê. Recuperado em 10 de maio de 2016, http://www.dcht16.uneb.br/revista/artigo1.pdf

ROSA, C. S. de S.(2005) Leitura: uma porta aberta na formação do cidadão. Recuperado em 20 de fevereiro de 2019, http://www.educacao.salvador.ba.gov.br/site/documentos/espaco-virtual/espacoautorias/artigos/leitura\%20$\% 20$ uma\%20porta\%20aberta....pdf

SILVA, E.T. (1998). Criticidade e leitura: ensaios. Campinas, SP: Mercado das Letras: Associação de Leitura do Brasil.

SILVA, J. A. da. (2011). Artigo de estudos de linguagem - Discutindo sobre leitura. UNIFAP, Amapá, Vol. 1, nº 1, p. 22-35.

SILVA, M. J. M. da, \& dos Santos, A. A. A. (2004). A avaliação da compreensão em leitura e o desempenho acadêmico de universitários. Recuperado em 02 de fevereiro de 2019, http://www.scielo.br/pdf/estpsi/v25n3/a08v25n3.pdf

SILVA, G. T. (2015). Interação entre leitura e escrita: o impacto dos hábitos de leitura e da mediação em leitura na escrita de alunos do ensino médio. Dissertação de mestrado, Universidade Católica do Rio Grande do Sul, PUC, Porto Alegre, RS, Brasil. Recuperado em 02 de fevereiro de 2019, http://repositorio.pucrs.br/dspace/bitstream/10923/7071/1/000466238-Texto\%2bCompleto0.pdf 
SOARES, M. (2000). As condições sociais da leitura: uma reflexão em contraponto. In: ZILBERMAN, R.; SILVA, E. T. (Org.). Leitura: perspectivas disciplinares. São Paulo: Ed. Ática.

SOARES, M. (2003). Letramento: um tema em três gêneros. Belo Horizonte: Autêntica.

SOUZA, M. C. de (2008). Práticas de leitura no espaço escolar: (Im) posição do docente e a formação do discente. Recuperado em 03 de junho de 2016, http://www.cultura.al.gov.br/politicas-e-acoes/sistema-estadual-debibliotecaspublicas/leituras-recomendadas/Praticas\%20 de\%20leitura\%20na\%20escola.pdf

THOMAZI, A. R. G. (2005) Práticas de leitura na escola: entre formação humana e formação escolar. Recuperado em 03 de maio de 2015,http://www.mestradoemgsedl.com.br/wp-content/uploads/2010/06/PR\%C3\%81TICASDELEITURA-NA-ESCOLA-Entre-Forma $\% \mathrm{C} 3 \% \mathrm{~A} 7 \% \mathrm{C} 3 \% \mathrm{~A} 3 \mathrm{o}-H u m a n a-\mathrm{eF}$ orma\%C3\%A7\%C3\%A3o-Escolar.pdf

VEIGA, L. \& Gondim, S.M.G. (2001). A utilização de métodos qualitativos na ciência política e no marketing político. Opinião Pública. 2 (1), 1-15.

VYGOTSKY, L.S. (1991). A formação social da mente. São Paulo: Martins Fontes.

VYGOTSKY, L.S (2008). Pensamento e linguagem. São Paulo: Martins Fontes.

Informações sobre os Revisores: \begin{tabular}{l|l} 
Língua Portuguesa & Nome completo: Valdemir Bezerra da Silva \\
& E-mail: prof.valbz@yahoo.com.br
\end{tabular}

Língua Inglesa

Nome completo: Valdemir Bezerra da Silva

E-mail: prof.valbz@yahoo.com.br

Língua Espanhola

Nome completo: Ana Cecília Oñativia

E-mail: aonativia@gmail.com 